\title{
Recovery Efficiency of Cumulus Oocyte Complexes (COCs) according to Collection Frequency for Ovum Pick-up (OPU) Method in Hanwoo Cow
}

\author{
Sung-Sik Kang, Ui-Hyung Kim, Seok-Dong Lee, Myung-Suk Lee, Man-Hye Han and Sang-Rae Cho*
}

Hanwoo Research Institute, NIAS, RDA, Pyeongchang 25340, Korea

Received December 2, 2019

Revised December 5, 2019

Accepted December 6, 2019

*Correspondence

Sang-Rae Cho

E-mail: chosr@korea.kr

ORCID

https://orcid.org/0000-0003-0209-6248

\begin{abstract}
This study was conducted to examine the oocyte recovery efficiency through having an OPU session once and twice a week. Also, the oocyte recovery efficiency was examined by using OPU after two and three months of rest period. Six cows were used for oocytes collection and were randomly divided into two groups. In experiment 1, OPU sessions were conducted once and twice a week to collect oocytes. The collected oocytes between once and twice OPU groups were classified into four groups (grade 1, 2, 3 and 4) according to the quality of cumulus cells and ooplasm. Based on the result, the percentage of collected oocytes per aspirated follicle number was similar between once and twice OPU session groups $(65.5 \pm 1.9$ and $68.7 \pm 1.4$ vs.). However, the percentage of grade 1 oocytes from the twice OPU session group was significantly high compared with that of the once a week OPU session group ( $25.3 \pm 0.9$ and $32.5 \pm 1.2 \%$ vs. once and twice session group, respectively, $p<0.05$ ). In experiment 2 , the group with three months of rest period tended to have a high percentage of collected oocyte compared with the group with two months of rest period (64.6 and $70.9 \%$ vs. 2 and 3 months rest group, respectively, $p=0.62$ ). The percentage of grade 4 in the group with three months of rest period was significantly low compared with the group with two months of rest period group ( 27.3 and $36.5 \%$ vs. two and three months rest group, respectively, $p=0.05)$. In conclusion, twice a week OPU session is suitable for collection of high quality oocytes by using OPU, and three months of rest period is needed for the recovery of oocyte quality of a donor cow.
\end{abstract}

Keywords: COCs, Hanwoo, OPU

\section{INTRODUCTION}

The multiple ovulation and embryo transfer method (MOET) is an important reproductive tool in dairy and beef cattle industry. The improvement of genetically valuable cow and elite bulls will be accelerated by using the MOET method. Recently, the tool for embryo production system in vivo using MOET has been changed with ovum pick up (OPU) with ultrasound guided probe, and in vi- tro embryo production method. Collection of cumulus oocyte complexed (COCs) by using the OPU method has been suggested by researchers in Denmark (Callesen et al., 1987). Repeatable oocyte recovery techniques were conducted by using endoscope method of Canadian researchers. The OPU method has several merits. There was no hormone treatment for in vivo embryo production and the use of donor cow short periods is easily compared with the MOET method. In Hanwoo cattle, the calves are 
produced by using OPU and in vitro embryo production (OPU-IVP), and embryo transfer method. The OPU method needs high and stable skills for recovery of COCs from live donor cows. There is improvement of recovery rate per number of COCs in ovaries and production of transferable embryos when OPU method is adapted to the collection of COCs and embryo production in vitro. However, there were many problems for embryos derived from MOET and OPU-IVP methods between individual cows (Yang et al., 2008, Pontes et al., 2011). This OPU method can be conducted two times per week, in case donors did not have any side effect by undergoing the OPU procedure (Galli et al., 2001). The aim of OPU method is to collect high quality of COCs and increase usable COCs for in vitro fertilization (Bols et al., 2004). The COCs collection methods affect its recovery rate and quality. The OPU probe with different frequency affects COCs recovery rate due to the difference in follicle image clarification (Hashimoto et al., 1999). Different vacuum pressures in OPU procedure also affect COCs' recovery rate and different COCs' quality induced with different blastocyst developmental rate after IVF (Ward et al., 2000). The type of OPU convex and linear transducer also showed a difference in the number of follicle confirmation on the surface of the ovary which resulted in different COCs recovery rate (Seneda et al., 2003). The frequency of OPU session (one or two times) per week also induced different follicle response and COCs recovery rate (Chaubal et al., 2006). Therefore, to achieve high quality recovery of COCS by using the OPU method, control of COCs collection technique by trained technician and OPU equipment with different probe, vacuum pressure, and OPU frequency, is needed. Two OPU sessions in a week for five months did not affect the blastocyst developmental rate (Kruip et al., 1994). However, pregnancy rate after the embryo transfer was significantly different between OPU session periods for one to four months. The transferred embryos derived from the first months of OPU session showed significantly high pregnancy rate compared with the second to fourth months (Jin et al., 2016). Previous researchers reported the effect of OPU session interval on pregnancy rate after ET. However, there were few reports for recovery periods of cow's body condition after an OPU. Thus, in the present study, we examined effect of collection efficiency by one and two OPU frequency in a week. Then, we examined COCs recovery rate after two or three months of resting period to verify the restoration of body condition as donor cow.

\section{MATERIALS AND METHODS}

\section{Selection of cows for experiment and feed management}

In the present study, six Hanwoo cows or heifers were used in Hanwoo Research Institute, National Institute of Animal Science, Rural Development Administration (RDA), Republic of Korea. Hanwoo cows with normal estrus cycle and normal body condition score $(2.5-3.0)$ were used as a donor. Formulated concentrate $(3 \mathrm{~kg} /$ day) and hay (rice straw, $6 \mathrm{~kg} /$ day) were fed to the individual Hanwoo cows. The chemical composition of formulated concentrates to donor cows are shown below: $12.4 \%$ moisture, $13.6 \%$ crude protein, $1.5 \%$ ether extract, $9.34 \%$ crude fiber, crude ash $4.79 \%, 0.72 \%$ calcium, and $0.53 \%$ P. chemical composition of hay were as below: $11.64 \%$ moisture, $5.91 \%$ crude protein, $0.23 \%$ ether extract, $7.48 \%$ crude fiber, 4.44 $\%$ crude ash, $0.17 \%$ calcium and $0.53 \% \mathrm{P}$.

\section{Collection of COCs from donor Hanwoo cows and classification of COCs grade}

COCs were collected by using OPU procedure once and twice a week. The donor cows were restrained by using a restraining frame, $7 \mathrm{mg}$ Xylazine HCL $0.2 \mathrm{~mL}$ (Rompun, Bayel corp.), injected in the jugular vein, and was given caudal epidural anesthesia with $5 \mathrm{~mL}$ of $2 \%$ lidocaine. The ovarian follicles were seen by using ultrasound-guided probe (7.5 MHz convex scanner, MyLabTM30-VETGOLD, Esaote, Genova, Italy). Follicles with the size of 2 to 8 $\mathrm{mm}$ were aspirated by using probe with $19 \mathrm{G}$ needle. The vacuum pressure was maintained with $60-80 \mathrm{mmHg}(10-$ $15 \mathrm{~mL} / \mathrm{min})$. To prevent coagulation of blood and oocyte, HEPES solution with $10 \mathrm{IU} / \mathrm{mL}$ heparin was used for aspiration and collection COCs. The aspirated follicular fluids were collected by using $50 \mathrm{~mL}$ tube and were transferred to the laboratory. Recovered COCs were classified to grade 1 to 4 under stereomicroscope by compactness and thickness of cumulus cells. COCs with grade 1 have normal morphological ooplasm and compactness cumulus cells. While COCs with grade 2 showed some cumulus cells were detached and cumulus cells were normal. The COCs with grade 3 showed degenerated cumulus cells and abnormal ooplasm, and COCs with grade 4 showed that 
almost cumulus cells were degenerated and detached.

\section{Experimental design}

In experiment 1 , we compared the number and quality of COCs between once and twice a week OPU session. Six cows were divided into two groups. The first group conducted one OPU session in a week. In total, eight times of OPU sessions were conducted in individual donor cows. The second group conducted a twice a week OPU session. Overall, 13 to 14 OPU sessions were conducted in individual donor cows. In experiment 2 , we compared the effect of rest periods of cows on the number of oocytes by using an OPU. After collecting COCS for two months, the first group with two cows took two months of rest. The second group with two cows took three months of rest. After which, the COCs were collected by using OPU twice a week. A total of 26 OPUs sessions were conducted in each group. The number of recovered COCs and the grade of COCs were examined.

\section{Statistical analysis}

The mean of COCs graded between one and two times OPU interval groups were compared by using one way ANOVA with General Linear Model. A $p$ value of $\leq 0.05$ was considered significantly different.

\section{RESULTS AND DISCUSSION}

In the present study, we examined COCs recovery ef- ficiency between once and twice a week OPU session groups. Moreover, the effect of resting periods was compared between two and three months after finishing the OPU procedure. In Table 1 , the COCs recovery efficiency in one OPU session in a week is shown. The COCs recovery rate in cow A showed a total number of 120 aspirated follicles and $74(61.7 \%)$ recovered COCs. The percentage of grade 1 was $24.3 \%(18 / 74)$ and percentage of grade was 23.0\% (17/74). In, Hanwoo B, 88 follicles were aspirated and $59(67.0 \%)$ COCs were collected. The percentage of grade 1 was $27.1 \%(16 / 59)$ and percentage of grade 2 was $22 \%(13 / 59)$. In Hanwoo cow C, the COCs recovery efficiency was $67.8 \%(57 / 84)$. The percentage of grade 1 was $24.6 \%(14 / 57)$ and percentage of grade 2 was $31.6 \%$ (18/57). In Table 2, COCs recovery efficiency in twice OPU sessions in a week are shown. In Hanwoo cow D, 162 follicles were aspirated and 115 COCs were collected. Its COCs recovery efficiency rate was $70.9 \%$. The percentage of grade 1 was $30.4 \%(35 / 115)$ and percentage of grade 2 was 17.4\% (20/115). In Hanwoo cow E, 217 follicles were aspirated and 150 COCs were recovered (69.1\%). The percentage of grade 1 was $34.7 \%(52 / 150)$ and percentage of grade 2 was $25.3 \%$ (38/150). In Hanwoo cow F, 271 follicles were aspirated and 179 COCs were recovered (66.1\%). The percentage of grade 1 was $32.4 \%(58 / 179)$ and percentage of grade was $17.3 \%(31 / 179)$. As shown Table 3, there was no difference in oocyte recovery rate between once and twice OPU session groups. Percentage of grade 2-4 between once and twice a week OPU session

Table 1. Recovery efficiency of oocytes and oocytes grade according to one time OPU session in a week in Hanwoo cows

\begin{tabular}{|c|c|c|c|c|c|c|c|c|}
\hline \multirow{2}{*}{$\begin{array}{l}\text { OPU frequency } \\
\text { (/week) }\end{array}$} & \multirow{2}{*}{ Donor } & \multirow{2}{*}{ Sessions } & \multirow{2}{*}{$\begin{array}{c}\text { No. follicle } \\
\text { (Mean } \pm \text { SD) }\end{array}$} & \multirow{2}{*}{$\begin{array}{l}\text { No. collected } \\
\text { oocytes (\%) }\end{array}$} & \multicolumn{4}{|c|}{ Oocytes grade (\%) } \\
\hline & & & & & $\mathrm{G} 1$ & $\mathrm{G} 2$ & G3 & G4 \\
\hline \multirow[t]{3}{*}{ Once } & A & 8 & $120(15.0 \pm 3.86)$ & $74(61.7)$ & $18(24.3)$ & $17(23)$ & $17(23)$ & $22(29.7)$ \\
\hline & B & 8 & $88(11.0 \pm 2.45)$ & $59(67.0)$ & $16(27.1)$ & $13(22.0)$ & $17(28.8)$ & $13(22.1)$ \\
\hline & C & 8 & $84(10.5 \pm 2.20)$ & $57(67.8)$ & $14(24.6)$ & 18 (31.6) & $11(19.3)$ & $14(24.5)$ \\
\hline
\end{tabular}

G1: Grade 1, G2: Grade 2, G3: Grade 3, G4: Grade 4.

Table 2. Recovery efficiency of oocytes and oocytes grade according to twice OPU session in a week in Hanwoo cows

\begin{tabular}{|c|c|c|c|c|c|c|c|c|}
\hline \multirow{2}{*}{$\begin{array}{l}\text { OPU frequency } \\
\text { (/week) }\end{array}$} & \multirow{2}{*}{ Donor } & \multirow{2}{*}{ Sessions } & \multirow{2}{*}{$\begin{array}{l}\text { No. follicle } \\
\text { (Mean } \pm \text { SD) }\end{array}$} & \multirow{2}{*}{$\begin{array}{l}\text { No. collected } \\
\text { oocytes (\%) }\end{array}$} & \multicolumn{4}{|c|}{ Oocytes grade (\%) } \\
\hline & & & & & $\mathrm{G} 1$ & $\mathrm{G} 2$ & G3 & G4 \\
\hline \multirow[t]{3}{*}{ Twice } & D & 14 & $162(11.57 \pm 2.98)$ & $115(70.9)$ & $35(30.4)$ & $20(17.4)$ & $25(21.7)$ & $35(30.5)$ \\
\hline & $E$ & 14 & $217(15.5 \pm 3.06)$ & $150(69.1)$ & $52(34.7)$ & $38(25.3)$ & $37(24.7)$ & $23(15.3)$ \\
\hline & $\mathrm{F}$ & 14 & $271(20.84 \pm 5.27)$ & $179(66.1)$ & $58(32.4)$ & $31(17.3)$ & $34(19.0)$ & $56(31.3)$ \\
\hline
\end{tabular}

G1: Grade 1, G2: Grade 2, G3: Grade 3, G4: Grade 4. 
Kang et al. Studies on Recovery Efficiency of COCs by OPU Method in Hanwoo Cows

Table 3. Comparison of recovery efficiency of oocytes and oocytes grade according to once and twice OPU session in a week in Hanwoo cows

\begin{tabular}{|c|c|c|c|c|c|c|c|c|}
\hline $\begin{array}{l}\text { OPU frequency } \\
\text { (/week) }\end{array}$ & $\begin{array}{l}\text { No. donor } \\
\text { cow }\end{array}$ & Sessions & $\begin{array}{l}\text { No. follicle } \\
\text { (Mean } \pm \text { SD) }\end{array}$ & $\begin{array}{l}\text { No. collected } \\
\text { oocytes (\%) }\end{array}$ & \multicolumn{4}{|c|}{ Oocytes grade (\%) } \\
\hline Once & 3 & 24 & $292(12.17 \pm 3.47)$ & $65.5 \pm 1.9$ & $25.3 \pm 0.9^{b}$ & $20.0 \pm 2.7$ & $23.7 \pm 2.8$ & $25.4 \pm 2.2$ \\
\hline
\end{tabular}

G1: Grade 1, G2: Grade 2, G3: Grade 3, G4: Grade 4.

a, bValues with different superscripts differ significantly between once and twice OPU session groups $(p<0.01)$.

Table 4. Comparison of oocyte recovery efficiency by using OPU after two and three months of recovery periods in Hanwoo cows

\begin{tabular}{ccccccccc}
\hline $\begin{array}{c}\text { Recovery } \\
\text { period (month) }\end{array}$ & $\begin{array}{c}\text { No. donor } \\
\text { cow }\end{array}$ & $\begin{array}{c}\text { OPU } \\
\text { session }\end{array}$ & $\begin{array}{c}\text { No. of aspirated fol- } \\
\text { licles }\end{array}$ & $\begin{array}{c}\text { No. of recovered } \\
\text { oocytes (\%) }\end{array}$ & \multicolumn{3}{c}{ Grade number of oocytes (\%) } \\
\hline 2 & 2 & 26 & 395 & $255(64.6)$ & $57(22.4)$ & $43(16.9)$ & $62(24.3)$ & $93(36.5)^{a}$ \\
3 & 2 & 22 & 429 & $304(70.9)^{\dagger}$ & $67(22.0)$ & $67(22.0)$ & $87(28.6)$ & $83(27.3)^{b}$ \\
\hline
\end{tabular}

G1: Grade 1, G2: Grade 2, G3: Grade 3, G4: Grade 4.

†Values with superscript mean that the group with three months recovery period tend to have high grade number of oocytes compared with the groups with two months recovery period $(p<0.06)$.

${ }^{a, b}$ Values with different superscripts differ significantly between two and three months of recover groups $(p<0.05)$.

group were not significantly different. However, percentage of grade 1 of twice a week OPU session group was significantly higher than that of once a week OPU session group $(68.7 \pm 1.4$ and $65.5 \pm 1.9$ vs. once and twice OPU session groups, $p<0.01$ ). This result means that twice a week OPU session was more efficient for collection of high quality oocytes compared with once a week OPU session group. Oocytes collection efficiency were not consistent with twice a week use of OPU procedure, weekly and biweekly (Konrad et al., 2017) and optimal OPU interval has not been determined due to different feeding system, condition of donor cow, and different OPU system. On the other hand, collection of high quality and high number of oocytes by using OPU will produce high quality blastocyst production. It is reported that 8 to 10 COCs were collected in an OPU session, and two transferrable blastocysts were produced after IVF (Galli et al., 2001). The number of blastocyst were derived from follicle stimulating hormone which was higher than nontreatment of hormone in donor cow (hormone treatment and non-treatment groups vs. 1.38 and 0.96). However, the hormone treatment to the donor cow induced a different number of follicles in surface of ovaries due to different estrus cycle was between individual donor cows (Paul et al., 1995). The mean of the collected COCs by twice a week OPU sessions were not significantly different between donor cows with hormone treatment and nontreatment group. In Holstein cows, the mean collected COCs between hormone treatment and non-treatment OPU session group in a week were similar $(15.7 \pm 3.3$ and $14.2 \pm 1.9$ vs. one time and twice OPU sessions) (Stubbings and Walton, 1995). In Table 4, oocyte recovery efficiency after two and three months of recovery periods in Hanwoo cows is shown. Four Hanwoo donor cows were randomly selected for collection of oocytes by using OPU. The number of recovered oocytes in three months-group tended to be high compared with two months-group ( $p<$ 0.062 ). The number of oocyte in grade 1,2 and 3 between 2 and 3 months groups did not have significant difference. However, the number of grade 4 oocytes in three months was significantly low compared with the two months group (36.5 and $27.3 \%$ vs. two and three months, respectively, $p<0.05)$. This result means that, recovery periods for three months was effective for oocyte collection by using OPU compared with two months of recovery period after donor cow. Previous reports have been focused only on the times an OPU session can be repeatedly done from donor cow and the change in the number of collected oocytes for long periods (Konrad et al., 2017). Kruip et al. (1994) reported that the collected number of oocytes were similar between two and five months of OPU experiments. However, conflict results were reported 
that twice a week OPU sessions in over 68 days can reduce follicle turnover in donor cow (Neglia et al., 2011). Therefore, an OPU experiment after three months of rest period is needed for recovery of follicular wave in donor cow, and it is recommend for collection of oocytes by using OPU.

In conclusion, twice a week OPU session is more efficient to collect good quality of oocytes from donor cows compared to once a week OPU session group. In addition, the rest period for three months will induce an increase in the total number of oocytes and decease low quality of oocytes by using OPU. Further, we should examine the embryo production and embryo quality using oocytes from donor cows with two and three rest periods.

\section{CONFLICTS OF INTEREST}

No potential conflict of interest relevant to this article was reported.

\section{ACKNOWLEDGEMENTS}

This study was supported by 2019 RDA Fellowship Program of Hanwoo Research Institute, Rural Development Administration, Republic of Korea. This work was carried out with the support of "Cooperative Research Program for Agriculture Science \& Technology Development (project title: Development of production technique for same offspring using OPU Hanwoo oocytes, Project No. PJ010291032018)" Rural Development Administration, Republic of Korea.

\section{AUTHOR'S AFFILIATION, POSITION AND ORCID NO.}

\author{
SS Kang, NIAS, Postdoctoral Fellow, \\ https://orcid.org/0000-0002-9453-5377 \\ UH Kim, NIAS, Researcher, \\ https://orcid.org/0000-0002-2197-5080 \\ SD Lee, NIAS, Research Assistant, \\ https://orcid.org/0000-0002-4481-5338 \\ MS Lee, NIAS, Research Assistant, \\ https://orcid.org/0000-0002-9111-8535 \\ MH Han, NIAS, Researcher, \\ https://orcid.org/0000-0002-8104-4587 \\ SR Cho, NIAS, Researcher, \\ https://orcid.org/0000-0003-0209-6248
}

\section{REFERENCES}

Bols, P. E. J., Leroy, J. L. M. R., Vanholder, T. \& Van Soom, A. 2004. A comparison of a mechanical sector and a linear array transducer for ultrasound-guided transvaginal oocyte retrieval (OPU) in the cow. Theriogenology, 62:906-914.

Chaubal, S. A., Molina, J. A., Ohlrichs, C. L., Ferre, L. B., Faber, D. C., Bols, P. E. J., Riesen, J. W., Tian, X. \& Yang, X. 2006. Comparison of different transvaginal ovum pick-up protocols to optimise oocyte retrieval and embryo production over a 10week period in cows. Theriogenology, 65:1631-1648.

Galli, C., Crotti, G., Notari, C., Turini, P., Duchi, R. \& Lazzari, G. 2001. Embryo production by ovum pick up from live donors. Theriogenology, 55:1341-1357.

Hashimoto, S., Takakura, R., Minami, N. \& Yamada, M. 1999. Ultrasound-guided follicle aspiration: Effect of the frequency of a linear transvaginal probe on the collection of bovine oocytes. Theriogenology, 52:131-138.

Jin, J. I., Ghanem, N., Kim, S. S., Choi, B. H., Ha, A. N., Lee, K. L., Sun, D. W., Lim, H. T., Lee, J. G. \& Kong, I. K. 2016. Interaction of donor age, parity and repeated recovery of cumulus-oocyte complexes by ovum pick-up on in vitro embryo production and viability after transfer. Livestock Science, 188:43-47.

Konrad, J., Clerico, G., Garrido, M. J., Taminell, G., Yuponi, M., Yuponi, R., Crudeli, G. \& Sansinena, M. 2017. Ovum pick-up interval in buffalo (Bubalus bubalis) managed under wetland conditions in Argentina: Effect on follicular population, oocyte recovery, and in vitro embryo development. Animal Reproduction Science, 183:39-45.

Kruip, T. A. M., Boni, R., Wurth, Y. A., Roelofsen, M. W. M. \& Pieterse, M. C. 1994. Potential Use of Ovum Pick-up for Embryo Production and Breeding in Cattle. Theriogenology, 42:675-684.

Neglia, G., Gasparrini, B., Vecchio, D., Boccia, L., Varricchio, E., Di Palo, R., Zicarelli, L. \& Campanile, G. 2011. Long term effect of Ovum Pick-up in buffalo species. Animal Reproduction Science, 123:180-186.

Pontes, J. H. F., Sterza, F. A. M., Basso, A. C., Ferreira, C. R., Sanches, B. V., Rubin, K. C. P. \& Seneda, M. M. 2011. Ovum pick up, in vitro embryo production, and pregnancy rates from a large-scale commercial program using Nelore cattle (Bos indicus) donors. Theriogenology, 75:1640-1646.

Seneda, M. M., Esper, C. R., Garcia, J. M., Andrade, E. R., Binelli, M., Oliveira, J. A. \& Nascimento, A. B. 2003. Efficacy of linear and convex transducers for ultrasound-guided transvaginal follicle aspiration. Theriogenology, 59:1435-1440.

Stubbings, R. B. \& Walton, J. S. 1995. Effect of UltrasonicallyGuided Follicle Aspiration on Estrous-Cycle and Follicular Dynamics in Holstein Cows. Theriogenology, 43:705-712.

Ward, F. A., Lonergan, P., Enright, B. P. \& Boland, M. P. 2000. Factors affecting recovery and quality of oocytes for bovine embryo production in vitro using ovum pick-up technology. Theriogenology, 54:433-446.

Yang, X. Y., Zhao, J. G., Li, H., Liu, H. F., Huang, Y., Huang, S. Z., Zeng, F. Y. \& Zeng, Y. T. 2008. Effect of individual heifer oocyte donors on cloned embryo development in vitro. Animal Reproduction Science, 104:28-37. 